\title{
Novel integrated microdialysis-amperometric system for in vitro detection of dopamine secreted from PC12 cells: Design, construction, and validation
}

\author{
Rossana Migheli ${ }^{a}$, Giulia Puggioni ${ }^{a}$, Sonia Dedola ${ }^{a}$, Gaia Rocchitta ${ }^{a}$, Giammario Calia ${ }^{a}$, Gianfranco Bazzu ${ }^{a}$, \\ Giovanni Esposito $^{\text {a }}$, John P. Lowry ${ }^{\mathrm{b}}$, Robert D. O’Neill ${ }^{\mathrm{c}}$, M.S. Desole ${ }^{\mathrm{a}}$, Egidio Miele ${ }^{\mathrm{a}}$, Pier A. Serra ${ }^{\mathrm{a}, *}$ \\ a Department of Neuroscience, Medical School, University of Sassari, 07100 Sassari, Italy \\ ${ }^{\mathrm{b}}$ Department of Chemistry, National University of Ireland, Maynooth, Co. Kildare, Ireland \\ 'School of Chemistry and Chemical Biology, University College Dublin, Belfield, Dublin 4, Ireland
}

\section{A R T I C L E I N F O}

\section{Article history:}

Received 25 May 2008

Available online 5 June 2008

\section{Keywords:}

Microdialysis

Dopamine

PC12

Secretion

Microsensor

Amperometry

Potentiostat

\begin{abstract}
A B S T R A C T
A novel dual channel in vitro apparatus, derived from a previously described design, has been coupled with dopamine (DA) microsensors for the flow-through detection of DA secreted from PC12 cells. The device, including two independent microdialysis capillaries, was loaded with a solution containing PC12 cells while a constant phosphate-buffered saline (PBS) medium perfusion was carried out using a dual channel miniaturized peristaltic pump. One capillary was perfused with normal PBS, whereas extracellular calcium was removed from extracellular fluid of the second capillary. After a first period of stabilization and DA baseline recording, $\mathrm{KCl}(75 \mathrm{mM})$ was added to the perfusion fluid of both capillaries. In this manner, a simultaneous "treatment-control" experimental design was performed to detect $\mathrm{K}^{+}-$ evoked calcium-dependent DA secretion. For this purpose, self-referencing DA microsensors were developed, and procedures for making, testing, and calibrating them are described in detail. The electronic circuitry was derived from previously published schematics and optimized for dual sensor constant potential amperometry applications. The microdialysis system was tested and validated in vitro under different experimental conditions, and DA secretion was confirmed by high-performance liquid chromatography with electrochemical detection (HPLC-EC). PC12 cell viability was quantified before and after each experiment. The proposed apparatus serves as a reliable model for studying the effects of different drugs on DA secretion through the direct comparison of extracellular DA increase in treatment-control experiments performed on the same initial PC12 cell population.
\end{abstract}

(c) 2008 Elsevier Inc. All rights reserved.
Dopamine $(D A)^{1}$ is a catechol-like neurotransmitter that has been implicated in cognitive functions [1], in reward pathways [2], and in Parkinson's disease [3,4]. DA biochemical dynamics have been studied extensively both in vivo and in vitro using different techniques, including microdialysis [5-8] and voltammetry [9]. Indeed, oxidation of DA to the corresponding orthoquinone (DA-OQ) is pos-

\footnotetext{
* Corresponding author. Fax: +39079 228525.

E-mail address: paserra@uniss.it (P.A. Serra).

1 Abbreviations: DA, dopamine; DA-OQ dopamine-orthoquinone; NO, nitric oxide; HPLC-EC, high-performance liquid chromatography with electrochemical detection; 3-MT, 3-methoxytyramine; DOPAC, dihydroxyphenylacetic acid; HVA, homovanillic acid; UA, uric acid; AA, ascorbic acid; PBS, phosphate-buffered saline; EGTA, ethyleneglycoltetraacetic acid; $D C P$, dual channel potentiostat; $A D C$, analog-to-digital converter; DAC, digital-to-analog converter; IC, integrated circuit; OPA, operational amplifier; WE, working electrode (DA microsensor); RE, reference electrode; $\mathrm{AE}$ auxiliary electrode; USB, Universal Serial Bus; AUX-CE, auxiliary counter electrode; FTEC, flow-through electrochemical cell; DR, drug reservoir; FM, fluid mixer; DMEM, Dulbecco's modified Eagle's medium; EDTA, ethylenediaminetetraacetic acid; COMT, catechol-O-methyl-transferase; DAT, dopamine transporter.
}

sible on Nafion-coated carbon electrodes with a good selectivity against electrochemically oxidizable anions [10,11]:

$\mathrm{DA}(\mathrm{Ox}) \rightarrow \mathrm{DA}-\mathrm{OQ}+2 e^{-}+2 \mathrm{H}^{+}$

A wide variety of techniques have been used for studying in vitro DA secretion/release, and most of them use PC12 cells because they are capable of synthesizing, secreting, and metabolizing DA. The PC12 cell line, obtained from rat pheochromocytoma of the adrenal medulla, is also used as a tool to understand the biochemical mechanisms underlying the physiology and degeneration of central dopamine neurons [12-14]. In previous studies, we successfully used PC12 cells to investigate the mechanism of nitric oxide (NO) donor-induced DA secretion [7] and DA oxidative homeostasis in vitro $[6,8]$. In such studies, DA was quantified in microdialysates by high-performance liquid chromatography with electrochemical detection (HPLC-EC). The aim of the current research was to combine a modified device for in vitro microdialysis with a novel, dual channel amperometric system for the online detection of DA secreted from PC12 cells. The new electronics de- 
sign, derived from a previously published apparatus [15,16], allows simultaneous "treatment-control" experiments on the same initial cell suspension so as to detect drug-related DA secretion. Instead of measuring a single exocytotic event [13] or single-cell DA secretion [14], the proposed apparatus serves as a rapid and reliable model for studying the effects of different drugs on DA secretion from a large population $\left(\sim 10^{6}\right)$ of PC12 cells and performing a direct comparison of extracellular DA increase in treatment-control paradigms. The further miniaturization of the electronics and the integration with ultra miniature peristaltic pumps could permit the realization of a low-cost miniaturized device for rapid drug screenings in vitro.

\section{Materials and methods}

\section{Reagents and solutions}

All chemicals were analytical reagent grade and were used as supplied and dissolved in bidistilled deionized water (Milli-Q). DA, 3-methoxytyramine (3-MT), dihydroxyphenylacetic acid (DOPAC), homovanillic acid (HVA), uric acid (UA), and ascorbic acid (AA) were purchased from Sigma (Milano, Italy). Nafion perfluorinated resin solution ( $5 \%$ in aliphatic alcohols) was purchased from Aldrich (Milano, Italy). The phosphate-buffered saline (PBS) solution was made using $\mathrm{NaCl}(137 \mathrm{mM}), \mathrm{KCl}(2.7 \mathrm{mM}), \mathrm{Na}_{2} \mathrm{HPO}_{4}$ (8.1 mM), $\mathrm{KH}_{2} \mathrm{PO}_{4}$ (1.47 mM), $\mathrm{CaCl}_{2}(1.19 \mathrm{mM}), \mathrm{MgCl}_{2}(0.54 \mathrm{mM})$, and glucose $(7.5 \mathrm{mM})$ from Sigma and then adjusted to $\mathrm{pH} 7.4$. In calcium-free experiments, PBS solution was made without $\mathrm{CaCl}_{2}$ and adding ethyleneglycoltetraacetic acid (EGTA, $1 \mathrm{mM}$ ). The stock solutions of DA and 3-MT $(250 \mu \mathrm{M})$ were freshly prepared in water immediately before use. The concentrated solutions of DOPAC $(250 \mu \mathrm{M})$, HVA $(250 \mu \mathrm{M})$, and AA $(1 \mathrm{mM})$ were prepared in $0.01 \mathrm{M} \mathrm{HCl}$ and stored in the freezer for up to 1 week before use. UA solutions ( $1 \mathrm{mM}$ ) were made in $2 \mathrm{M} \mathrm{NaOH}$, stored at below $4^{\circ} \mathrm{C}$, and diluted in water before use.

\section{Materials and electronic components}

Electronic parts were obtained from the Farnell In One spa (Milano, Italy). The power section of the dual channel potentiostat (DCP) was stabilized using Linear voltage regulators (LM1086-5 and -3 ). The amperometric section of the DCP was built using six operational amplifiers (National LMC6042), whereas the differentiator-amplifiers were two AD626 units from Analog Devices. The 12-bit analog-to-digital converter (ADC)-digital-to-analog converter (DAC) system was built with integrated circuits from Maxim/Dallas and Analog Devices: MAX1270 (ADC), MAX5156 (DAC), and ADR370 (DAC-VRef). The MCU used in the DCP was the Propeller 32-bit multicore microcontroller (Parallax, Rocklin, CA, USA). The serial-to-USB converter was an FTDI FT232R controller (Future Technology Devices International, Glasgow, UK).

\section{$D C P$ design and construction}

The DCP was built as described previously [15] and includes two distinct parts: the amperometric and digital sections. The two-channel amperometric section (Fig. 1) was developed around the integrated circuit (IC) LMC6042, a dual single-supply operational amplifier (OPA). The following description concerns a single analog channel. The DAC (MAX5156) produces the voltage necessary to polarize the DA microsensor (working electrode [WE]) at $+250 \mathrm{mV}$ versus $\mathrm{Ag} / \mathrm{AgCl}$ reference electrode (RE). A two-OPA potentiostat controls the RE and the auxiliary electrode $(\mathrm{AE})$. The current-to-voltage $(\mathrm{I} / \mathrm{V})$ converter is a single-supply adaptation of a classical transimpedance amplifier [16] with a fixed gain depending on the value of Rf1-2 (10 M $\Omega$ ). The AD626-based difference amplifier has the dual function of removing the potential applied to the WE [17] while amplifying the resulting signal 100 times $(1 \mathrm{nA} / \mathrm{V})$. The core of the digital section was a Propeller, a 32-bit multicore CMOS IC containing eight independent controllers called COGs. The MCU, working at $80 \mathrm{MHz}$, controlled the ADC, the DAC, and the serial transmission of data to the PC. MCU peripherals have independent data and control lines to prevent hardware collisions during parallel computing. A Universal Serial Bus (USB) provided the stabilized power supply to the DCP.

\section{Firmware and software}

The Propeller firmware is developed in Spin, a specialized interpreted language, and then transferred to the MCU by an in-circuit serial programmer. The DA microsensor applied potentials $(+250 \mathrm{mV}$ vs. $\mathrm{Ag} / \mathrm{AgCl})$ are generated using a two-channel DAC controlled by two COGs. The resulting sensor currents are converted to digital values using two more COGs interfaced to a multichannel ADC. The remaining COGs perform digital signal processing and generate serial data for the interfacing PC via USB. Completely customizable data acquisition software, allowing the PC to record, plot, and display the received data, was developed in Visual Basic.NET 2008 using ZedGraph charting class library.

\section{DA microsensor and flow-through electrochemical cell}

The Nafion-coated WEs (DA microsensors) were made using Teflon-insulated silver wire $(30 \mathrm{~mm}$ in length, $\varnothing=250 \mu \mathrm{m}$, Advent Research Materials, Suffolk, UK). Approximately $1 \mathrm{~mm}$ of the wire was exposed and inserted in a glass micropipette filled partly with graphite-loaded $(55 \%, \mathrm{w} / \mathrm{w})$ epoxy resin (Araldite-M, Sigma-Aldrich). The 500- $\mu \mathrm{m}$ diameter carbon composite disk electrode (area $=0.0019 \mathrm{~cm}^{2}$ ) was fabricated by mixing $850 \mathrm{mg}$ of graphite (synthetic graphite powder, particle $\varnothing<20 \mu \mathrm{m}$, Sigma-Aldrich) with $500 \mathrm{mg}$ of Araldite-M and $200 \mathrm{mg}$ of harderer [18] and filling a precut $(10 \mathrm{~mm}) 10-\mu$ l glass micropipette (microcaps, Drummond Scientific, Broomall, PA, USA) with the mixture. The silver wire guaranteed a good electrical contact. After $24 \mathrm{~h}$ at $40^{\circ} \mathrm{C}$, the disk was polished using sandpaper (1200 grain) and diamond powder and Nafion treatment was performed (three coats and 20 min drying at $120^{\circ} \mathrm{C}$ ). DA oxidation potential was experimentally obtained at $+250 \mathrm{mV}$ versus $\mathrm{Ag} / \mathrm{AgCl}$ using cyclic voltammetry at $100 \mathrm{mV} / \mathrm{s}$ (CV37 voltammograph, Bioanalytical Systems, West Lafayette, IN, USA). DA microelectrodes were calibrated in quiescent conditions by adding known volumes of a standard DA solution in PBS. Only electrodes with DA detection limits $\leqslant 25 \mathrm{nM}$ and high selectivity against $A A(D A / A A>1000: 1)$ were used. No significant interference signals were observed on exposing sensors to other oxidizable anions (UA, DOPAC, and HVA) even at pharmacologically relevant concentrations (up to $0.5 \mu \mathrm{M}$ ). The pseudo-reference electrode (RE) and auxiliary counter electrode (AUX-CE), used in the flowthrough electrochemical cell (F-TEC), were an AgCl-coated silver wire and a $2-\mathrm{mm}$ platinum wire $(\emptyset=125 \mu \mathrm{m})$, respectively. RE was prepared by immersing $1 \mathrm{~mm}$ silver wire $(\varnothing=125 \mu \mathrm{m})$ in a saturated $\mathrm{KCl}$ solution and applying $+500 \mathrm{mV}$ for $1 \mathrm{~min}$. The WE, $\mathrm{RE}$, and CE were glued together using epoxy resin and soldered to a 2.54-mm PCB connector. The F-TEC was assembled using a portion of a 10- $\mu$ l Hamilton micropipette tip (inlet section) and a $250-\mu l$ microcentrifuge tube (Alpha Laboratories, Eastleigh, UK) (outlet section). The inlet and outlet sections were connected to $25 \mathrm{~mm}$ polyethylene tubing $(0.58 \mathrm{~mm}$ i.d., Portex, Hythe, UK). The final volume of the F-TEC was approximately $10 \mu \mathrm{l}$. A schematic diagram and picture of the F-TEC are shown in Fig. 2. Two 


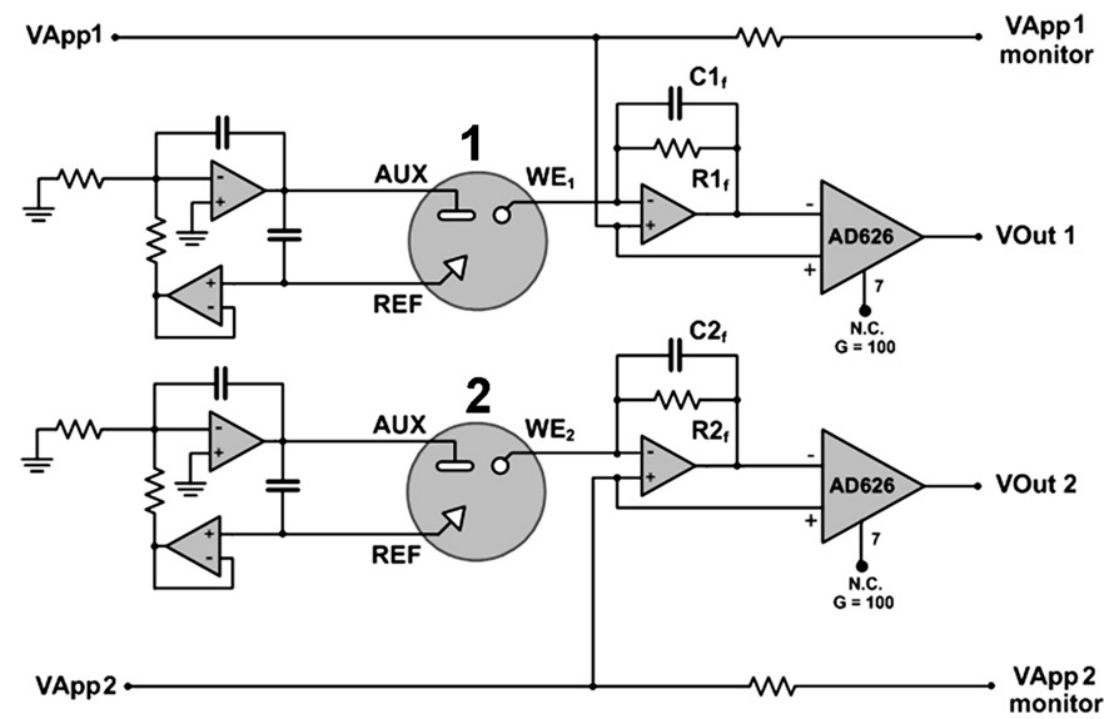

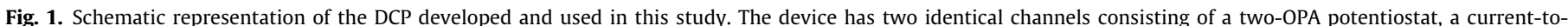

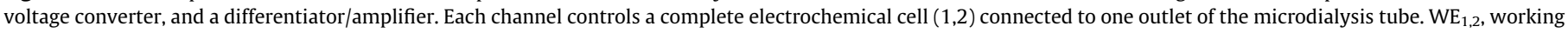
electrode (DA microsensor); REF, reference electrode (RE); AUX, auxiliary electrode; VApp $_{1,2}$, applied voltage (+250 mV vs. RE); VOut 1,2 , output voltage.

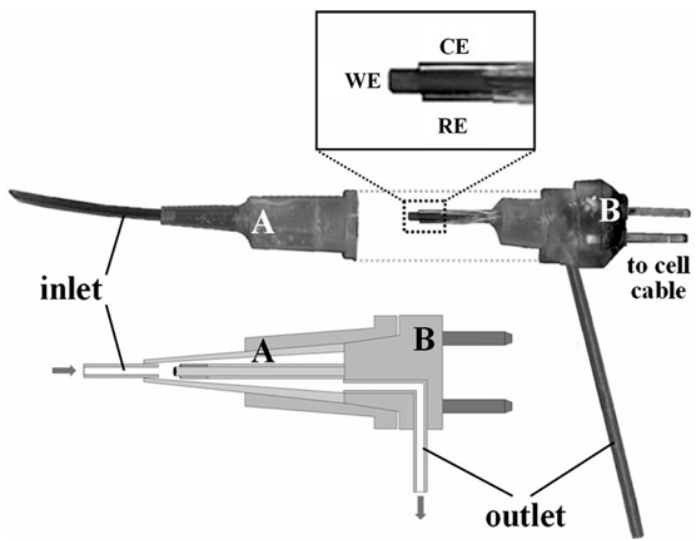

Fig. 2. Picture and schematic diagram of the F-TEC developed and used in this study. The cell is composed of an inlet section (A) and an outlet section (B) connected to one channel of the potentiostat through a cell cable. WE, working electrode (DA microsensor); RE, reference electrode; CE (AUX), counter (auxiliary) electrode.

F-TECs having similar DA responses were selected and used for each dual channel system.

\section{Capillary tube construction for in vitro microdialysis}

The capillary tube for microdialysis of PC12 cells (Fig. 3) is an adaptation of an in vitro device described previously [6-8]. The microdialysis probe was constructed using two sections of plastic-coated silica tubing $(150 \mu \mathrm{m}$ o.d., $75 \mu \mathrm{m}$ i.d., Scientific Glass Engineering, Milton Keynes, UK), each placed in the center of a semipermeable polyacrylonitrile dialysis fiber (AN-69, Hospal Industrie, Meyzieu, France). Each semipermeable membrane had an active length of $40 \mathrm{~mm}$. Then each section of plastic-coated silica tubing was positioned in the center of polyethylene tubing ( $0.58 \mathrm{~mm}$ i.d., $35 \mathrm{~mm}$ long, Portex). The two sections of silica tubing served as inlets. Dialysates from each polyacrylonitrile dialysis fiber were collected from polyethylene tubing, which served as outlets. Two more sections of plastic-coated silica tubing $(40 \mathrm{~mm}$ long) were sealed outside the polyethylene tubing for loading the PC12 cell suspension in two separate dialysis chambers. All parts

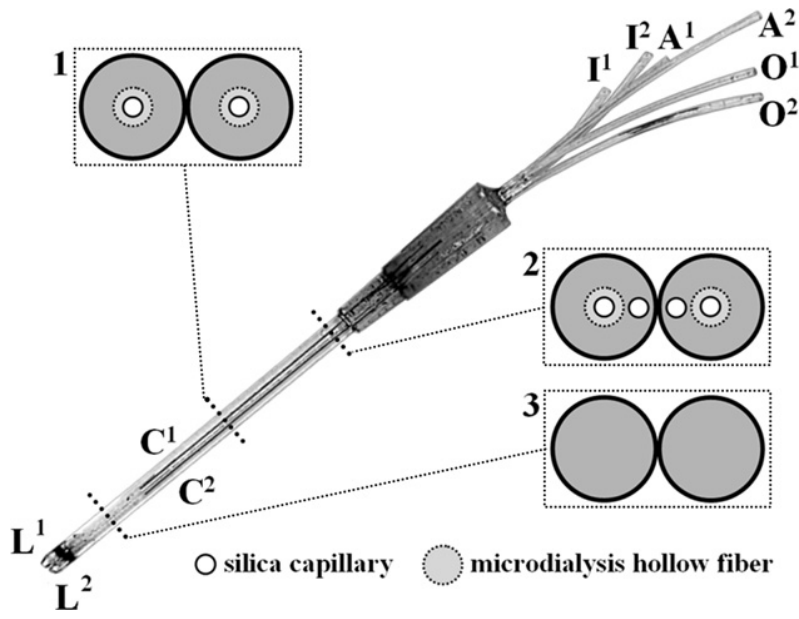

Fig. 3. Picture and schematic diagram of three sections (1-3) of the dual channel microdialysis tube used in this study. $C^{1,2}$, microdialysis capillaries; $\mathrm{I}^{1,2}$, inlet tubes: $\mathrm{O}^{1,2}$, outlet tubes; $\mathrm{A}^{1,2}$, aspiration tubes; $\mathrm{L}^{1,2}$, loading tips.

were coated with quick-drying epoxy glue. After that, microdialysis probes (semipermeable polyacrylonitrile dialysis fibers plus sealed plastic-coated silica tubing) were placed in two nonheparinized microhematocrit capillary tubes ( $7.5 \mathrm{~mm}$ long, $1.1 \mathrm{~mm}$ i.d., Chase Scientific Glass, Rockwood, IL, USA). The final volume of each microdialysis chamber was approximately $50 \mu$ l. Two distinct inlets and outlets allowed separate dialysate sample collection and separate pharmacological treatments. Two simultaneous and independent experiments could be performed at the same time using two samples of the same original PC12 cell suspension.

\section{Drug reservoir and fluid mixer}

A 50- $\mu$ l drug reservoir (DR) (Fig. 4, bottom left schematic) was assembled using a portion of a $100-\mu$ l Hamilton micropipette tip and a $250-\mu \mathrm{l}$ microcentrifuge tube (Alpha Laboratories). As shown in Fig. 4, the liquid normally flows in the DR using the main circuit (inlet 1 and outlet 3 ); an auxiliary circuit (inlet 2 and outlet 4 ) permits a change in the DR content by acting as injector. DR inlets and 


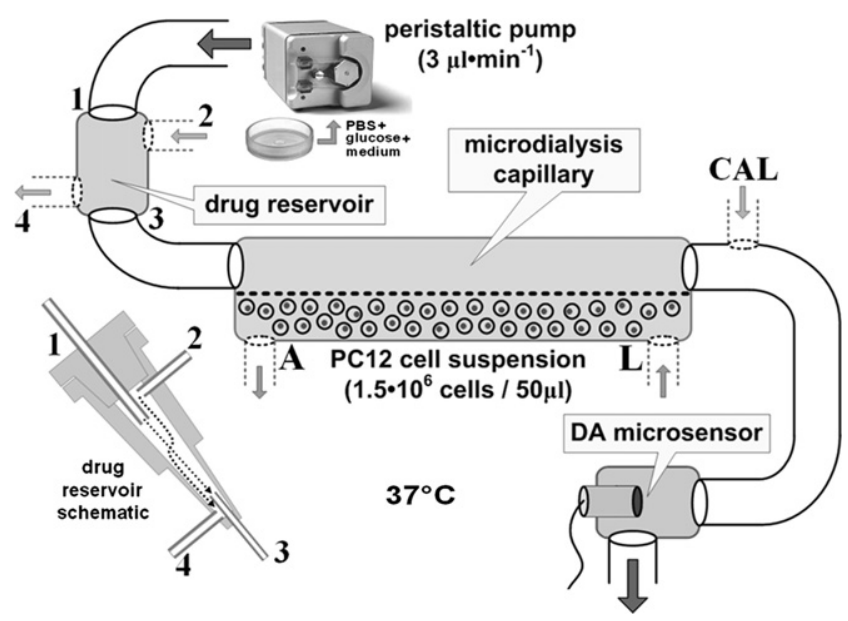

Fig. 4. Single channel schematic of the microfluidic system used in this study. A peristaltic micropump moves a PBS-based solution in the capillary tube passing through a drug reservoir $(1 \rightarrow 3)$ and carrying the drug loaded in it using an auxiliary circuit $(2 \rightarrow 4)$. PC12 cells were loaded $(\mathrm{L})$ in the microdialysis chamber by aspiration (A). A complete electrochemical cell, including a DA microsensor, is connected at the end of the circuit for online monitoring of DA secreted from PC12 cells. Direct DA microsensor calibration was performed using the CAL input.

outlets were constructed by cutting four needles: three having an external diameter of $22 \mathrm{G}(1,2$, and 4 in Fig. 4) and one having an external diameter of $27 \mathrm{G}$ (3 in Fig. 4). This technical detail facilitates DR loading with a drug-containing solution and ensures minimal impact on microdialysis tube microfluidics. A fluid mixer (FM) ( $\mathrm{a}$ and $\mathrm{b}$ in Fig. 5, top left schematic) was made using one 23-G needle (a) and $15 \mathrm{~mm}$ of plastic-coated silica tubing (b, CAL input in Fig. 4) (150 $\mu \mathrm{m}$, o.d., $75 \mu \mathrm{m}$ i.d., Scientific Glass Engineering). The needle was directly connected to the outlet of the microdialysis tube. Two DRs and two FMs were made for each dual channel system.

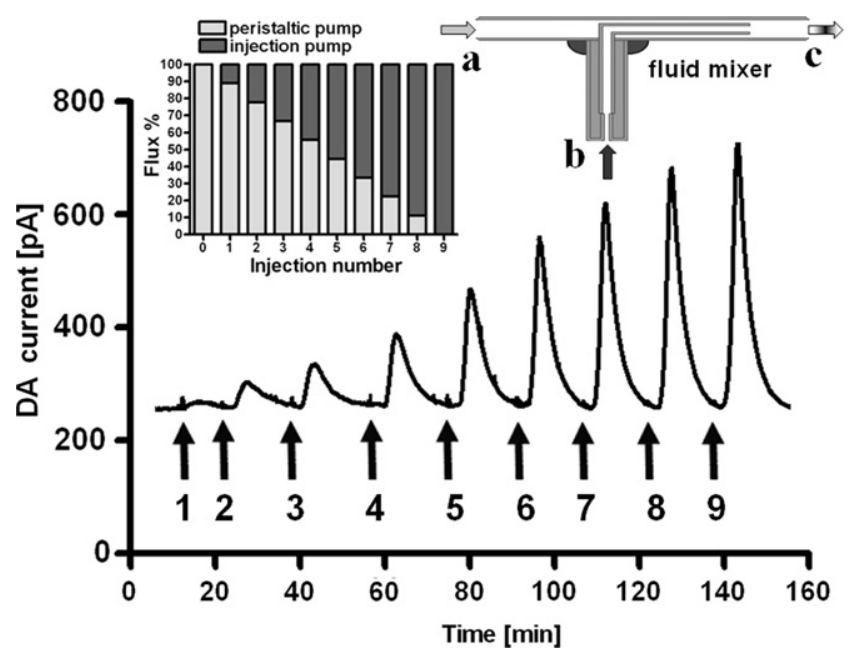

Fig. 5. Dynamic DA microsensor calibration performed bypassing the microdialysis tube. A microperistaltic pump and an injection pump, loading $1 \mu \mathrm{M}$ DA in PBS, were directly connected to the F-TEC using a miniaturized fluid mixer (FM). The calibration was performed with nine DA injections lasting 2 min each. Before and between injections, only the microperistaltic pump was active, running at $3 \mu \mathrm{l} / \mathrm{min}$. As shown in the top left inset graph, during DA injections (1-9, at arrows), a fixed flux of $3 \mu \mathrm{l} / \mathrm{min}(100 \%, \mathrm{FM}, \mathrm{c})$ was maintained, decreasing the microperistaltic flux $(-0.333 \mu \mathrm{l} / \mathrm{min} /$ injection, FM, a) and increasing the injection pump flux $(+0.333 \mu \mathrm{l} /$ min/injection, FM, b) and the DA concentration $(+0.111 \mu \mathrm{M} /$ injection $)$. A total of $6 \mu \mathrm{l}$ of DA-containing PBS reached the electrochemical cell after each 2-min injection (DA, 0-1 $\mu \mathrm{M})$.

\section{Cell culture}

PC12 cells were maintained at $37^{\circ} \mathrm{C}$ in $60-\mathrm{mm}$ plastic culture plates in a humidified atmosphere of $5 \% \mathrm{CO}_{2} / 95 \%$ air as described previously [19]. The formulation of the culture medium was as follows: Dulbecco's modified Eagle's medium (DMEM)-F12 supplemented with $10 \%$ horse serum and $5 \%$ fetal calf serum. After short-term culture [20] (15-20 passages), the cells were washed twice using $2 \mathrm{ml}$ of modified PBS and DMEM (10\%), harvested by trituration, and centrifuged (94g for $5 \mathrm{~min}$ ). Cells were resuspended in PBS-DMEM; thereafter, the number of cells $/ 50 \mu \mathrm{l}$ was assessed by trypan blue in a Burker chamber. The initial volume of the cell suspension was eventually adjusted to reach a final concentration of between $2.5 \times 10^{5}$ and $1.5 \times 10^{6} / 50 \mu$ l.

\section{Experimental procedure}

The experimental apparatus was assembled (Fig. 4), and currents were recorded until a stable baseline was obtained. DA microsensor calibration was performed before and after each experiment using the CAL inlet (Fig. 4) and following the procedure illustrated in Fig. 5. The cellular microdialysis tube was perfused with PBS-DMEM by means of a peristaltic microinfusion double channel pump (P720 peristaltic pump, Instech, Plymouth Meeting, PA, USA) at a flow rate of $3.0 \mu \mathrm{l} / \mathrm{min}$. PBS-DMEM was kept in a 60 $\mathrm{mm}$ plastic culture plate in an IR incubator at $37{ }^{\circ} \mathrm{C}$ in a humidified atmosphere of $5 \% \mathrm{CO}_{2} / 95 \%$ air. The pump channels were connected to the inlets by a length of polyethylene tubing. Each of the two microdialysis chambers ( $\mathrm{C} 1$ and $\mathrm{C} 2$ in Fig. 3 ) was then loaded with $50 \mu \mathrm{l}$ of PC12 suspension. The cell aspiration was performed manually by means of two $1.0-\mathrm{ml}$ syringes connected to the plasticcoated silica tubing sealed outside the polyethylene tubing ( 1 in Fig. 6A). Thereafter, the perfusion apparatus was kept at $37^{\circ} \mathrm{C}$ and DA currents were recorded for the entire time of the experiment. The DRs were loaded with $\mathrm{KCl} 120 \mathrm{~min}$ after cell loading (2 in Fig. 6A).

\section{Chromatographic analysis of dialysates from PC12 cell suspension}

DA was quantified in dialysates of selected experiments $\left(1.5 \times 10^{6}\right.$ cells $)$ by HPLC-EC, as described previously [6-8,19], using an Alltech 426 HPLC pump (Alltech, Sedriano, Italy) equipped with a Rheodyne injector (model 7725, Rohnert Park, CA, USA), a column $(15 \mathrm{~cm} \times 4.6 \mathrm{~mm}$ i.d., ODS80TM C18, Toso Haas, Stuttgart, Germany), an electrochemical detector ANTEC-Leyden EC controller (ANTEC, Zoeterwoude, The Netherlands), and a PC-based ADC system (Varian Star Chromatographic Workstation, Varian, Walnut Creek, CA, USA). The mobile phase was citric acid (0.1 M), ethylenediaminetetraacetic acid (EDTA, $1.0 \mathrm{mM}$ ), $\mathrm{MeOH}(8.7 \%)$, and sodium octylsulfate $(48 \mathrm{mg} / \mathrm{L})$, with a flow rate of $1.2 \mathrm{ml} / \mathrm{min}$ and $\mathrm{pH} 2.9$.

\section{Assessment of cell viability}

Trypan blue exclusion cell viability was assessed twice in the same PC12 suspension: before filling the capillary apparatus and at the end of each experiment ( $6 \mathrm{~h}$ after PC12 cell loading into the microdialysis tube). For each experiment, the viability rate was given as the difference between final and initial percentages of nonviable cells and as the difference between nonviable cells in each microdialysis chamber.

\section{Statistical analysis}

DA oxidation currents were expressed in picoamps (pA) and given as means \pm standard errors. Concentrations of DA were expressed in micromoles $(\mu \mathrm{M})$. After quiescent DA microsensor 
calibrations, linear regression was calculated between oxidation current and injected DA concentrations. Following dynamic DA microsensor calibrations and PC12 cell experiments, linear regression was performed using DA current values (peak height). Pearson's correlation coefficient was used to compare the correlation between the PC12-loading DA current and the KCl-induced DA current. The null hypothesis was rejected when $P<0.05$.

\section{Results}

\section{Quiescent and dynamic DA microsensor calibration}

All in vitro calibrations of DA microsensors were performed at $37{ }^{\circ} \mathrm{C}$ starting $24 \mathrm{~h}$ after F-TEC manufacturing and were repeated daily for up to 7 consecutive days. The system response to DA was tested in quiescent conditions by connecting each channel of the DCP to the outlet section of F-TEC comprising a DA microsensor and reference and counter electrodes (Fig. 2B). A 25-ml Teflon beaker was adapted as described in a previous article [16] and was used for calibration. Before the calibration procedure, the F-TEC$B$ was placed in the PBS-containing beaker and a constant potential of $+250 \mathrm{mV}$ versus $\mathrm{Ag} / \mathrm{AgCl}$ was applied. The calibration apparatus was placed on a stirrer until a stable baseline was reached. A 32mm-diameter magnetic bar was used to mix the solution after each addition of dopamine, and the resulting oxidation current was recorded after stirring. DA calibration in quiescent conditions (data not shown) displayed excellent linearity with a slope of $643 \pm 17 \mathrm{pA} \bullet \mu \mathrm{M}^{-1}\left(r^{2}=0.997, n=6\right)$. After 6 days, sensitivity decreased to $425 \pm 56 \mathrm{pA} \bullet \mu \mathrm{M}^{-1}$, maintaining good linearity $\left(r^{2}=0.986, n=6\right)$. Dynamic calibration of DA microsensors (Fig. 5) was performed under stable flux conditions ( $3 \mu \mathrm{l} / \mathrm{min}$ ) connecting the peristaltic pump and the microinjection pump to the FM. The linear regression was calculated using the DA peak height as current values (after each DA injection), with sensitivities of $553 \pm 21 \mathrm{pA} \bullet \mu \mathrm{M}^{-1} \quad\left(r^{2}=0.989, \quad n=6\right) \quad$ and $\quad 364 \pm 46 \mathrm{pA} \bullet \mu \mathrm{M}^{-1}$ $\left(r^{2}=0.997, n=6\right)$ being obtained on days 1 and 7 , respectively. For a detailed description of the dynamic calibration procedure, refer to figure legend of Fig. 5.

Effect of different DA concentrations in the microdialysis chamber and perfusion flux changes on DA current

In a first series of experiments performed 1 day after F-TEC construction, PBS solutions, containing different concentrations of DA, were loaded in the microdialysis chamber simulating a PC12 cell aspiration. DA currents, after a sequence of three consecutive loadings (250, 500, and $1000 \mathrm{nM})$, changed as described in Fig. 7A. The linear regression was calculated using the DA peak heights as current values (after each DA aspiration) and obtaining sensitivity of $464 \pm 44 \mathrm{pA} \bullet \mu \mathrm{M}^{-1}\left(r^{2}=0.982, n=6\right)$. In a second series of experiments, three consecutive fillings of the microdialysis chamber were performed with a PBS solution containing DA (250 nM) at different perfusion regimens: $6 \mu \mathrm{l} / \mathrm{min}, 3 \mu \mathrm{l} / \mathrm{min}$, and $1.5 \mu \mathrm{l} / \mathrm{min}$. The perfusion flux was changed before each DA aspiration, resulting in a variation of the DA oxidation peak height, as illustrated in Fig. 7B. The linear regression was calculated, and a decrease in DA sensitivity of $29 \pm 9 \mathrm{pA}\left(r^{2}=0.906, n=6\right)$ was observed for every microliter/minute increase in perfusion flow rate. A flux of $3 \mu \mathrm{l} / \mathrm{min}$ was selected to perform experiments with PC12 cells.

\section{Effect of PC12 cell number on DA secretion}

After three DA loadings and linear regression analysis (as described in the previous paragraph), the microdialysis chamber was rinsed with bidistilled water and PC12 cells were loaded as described in Materials and Methods (1 in Fig. 6A). Several experiments were performed, loading different numbers of cells
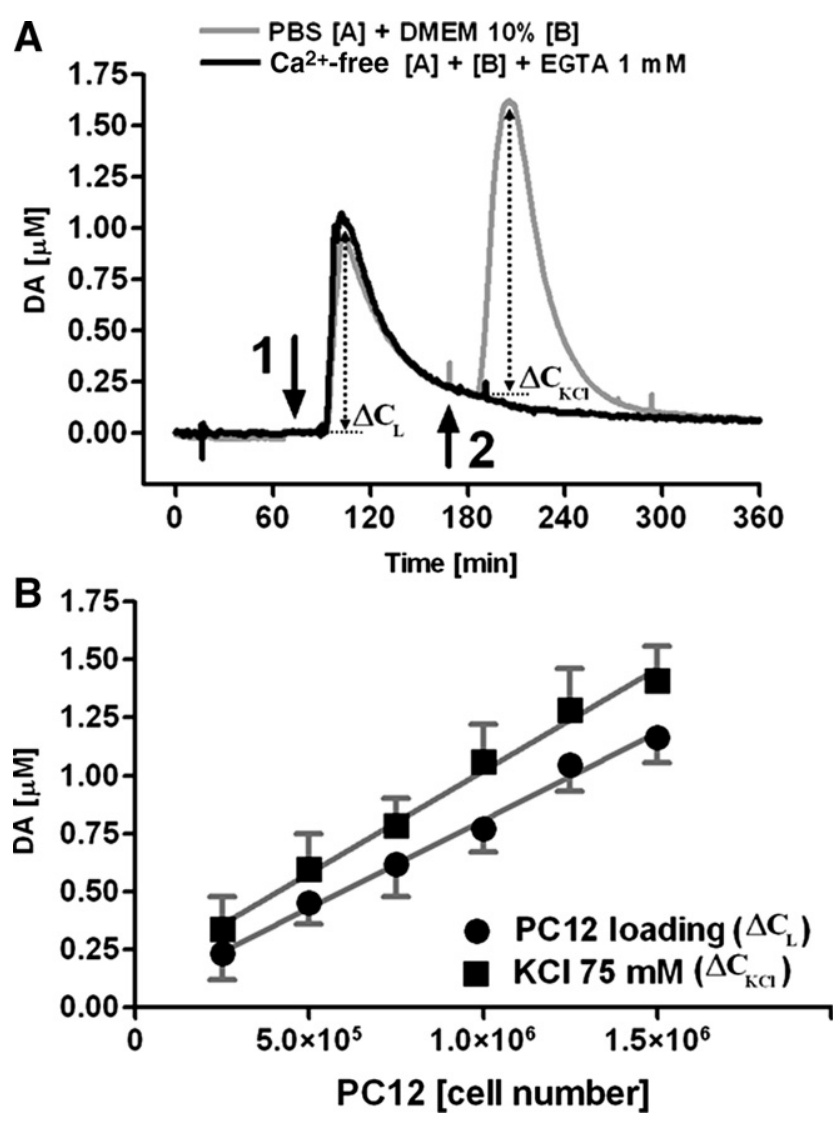

Fig. 6. (A) DA variations for $1.5 \times 10^{6} \mathrm{PC} 12$ cell loading $\left(\Delta C_{\mathrm{L}}, 1\right)$ and $\mathrm{KCl}(75 \mathrm{mM})$ injection $\left(\Delta C_{\mathrm{KCl}}, 2\right)$ recorded simultaneously in normal and $\mathrm{Ca}^{2+}$-free perfusion fluids (light and dark gray curves, respectively). (B) $\Delta C_{\mathrm{L}}$ and $\Delta C_{\mathrm{KCl}}$ plotted versus PC12 cell number ( $n=3$ for each cell number) (see text).

ranging from $2.5 \times 10^{5}$ to $1.5 \times 10^{6} / 50 \mu$ l. Then, 7 min after cell loading, a DA peak appeared (Fig. $6 \mathrm{~A}$ ) with a calculated concentration $\left(\Delta C_{\mathrm{L}}\right)$ proportional to the number of PC12 cells in the suspension. $\Delta C_{\mathrm{L}}$ was determined after each experiment, using the linear equation obtained from DA aspirations, and plotted versus PC12 cell number (Fig. 6B). Linear regression yielded sensitivity of $0.754 \pm 0.033 \mathrm{pM}(5.76 \pm 0.25 \mathrm{fg})$ per single PC12 cell loaded in the microdialysis chamber $\left(r^{2}=0.992, n=6\right)$. As illustrated in Fig. $6 \mathrm{~A}$, no differences in $\Delta C_{\mathrm{L}}$ were observed in either the presence or absence of $\mathrm{Ca}^{2+}$ in the perfusion fluid. Chromatographic analysis of dialysates showed a maximal initial DA concentration of $1.188 \pm 0.037 \mu \mathrm{M} / 1.5 \times 10^{6}$ cells and $0.136 \pm 0.023 \mu \mathrm{M} / 1.5 \times 10^{6}$ cells $120 \mathrm{~min}$ after PC12 loading, confirming previously reported data [7].

Effect of $\mathrm{KCl}$ on DA secreted from PC12 cells in either the presence or absence of extracellular $\mathrm{Ca}^{2+}$

The dual channel microdialysis apparatus was perfused using modified PBS in either the presence (channel 1) or absence (channel 2) of $\mathrm{CaCl}_{2}$. $\mathrm{KCl}(75 \mathrm{mM}$ ) was injected in both DRs (2 in Fig. 6A) 90 min after PC12 loading, and a DA secretion peak appeared $8 \mathrm{~min}$ later only in the presence of extracellular $\mathrm{Ca}^{2+}$ (Fig. 6A). The DA peak had a calculated concentration $\left(\Delta C_{\mathrm{KCl}}\right)$ proportional to PC12 cell number and extracellular $\mathrm{KCl}$ and $\mathrm{CaCl}_{2}$ (data not shown). $\Delta C_{\mathrm{KCl}}$ was plotted versus PC12 cell number (Fig. 6B), and linear regression was calculated with a resulting DA concentration of $0.88 \pm 0.04 \mathrm{pM}(6.7 \pm 0.3 \mathrm{fg})$ per single PC12 cell in the microdialysis chamber $\left(r^{2}=0.991, n=3\right)$. HPLC analysis of dialysates con- 

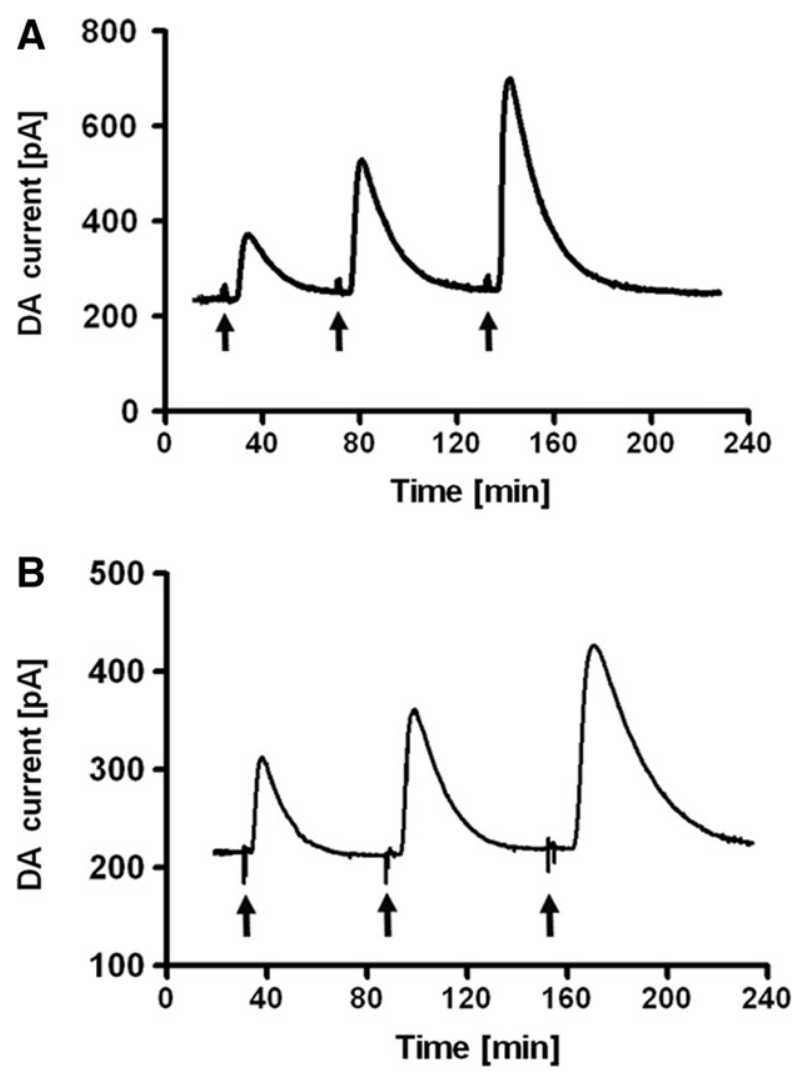

Fig. 7. DA current after a series of three consecutive loadings (at arrows) of PBS solution containing DA at different concentrations $(250,500$, and $1000 \mathrm{nM})$ and a fixed perfusion flow rate $(3 \mu \mathrm{l} / \mathrm{min})$ (A) or containing a fixed DA concentration $(250 \mathrm{nM})$ and different perfusion flow rates $(6,3$, and $1.5 \mu \mathrm{l} / \mathrm{min})(\mathrm{B})$. Aspirations in the microdialysis tube were performed as described for PC12 cell suspension loading (see text) using a 1-ml Hamilton syringe.

firmed a maximum DA concentration increase of $1.269 \pm 0.044 \mu \mathrm{M} / 1.5 \times 10^{6}$ cells $40 \mathrm{~min}$ after $\mathrm{KCl}$ injection [7]. Using Pearson's correlation coefficient, a significant correlation was found between $\Delta C_{\mathrm{L}}$ and $\Delta C_{\mathrm{KCl}}$ mean values $(r=0.9953$, $r^{2}=0.991, P<0.0001, x y$ pairs $=6$ ). No $\mathrm{K}^{+}$-evoked DA secretion was observed in the absence of extracellular $\mathrm{Ca}^{2+}$ (Fig. 6A).

\section{PC12 cell viability before and after microdialysis experiments}

The assessment of cell viability was performed as described in Materials and Methods. After an initial preparation, the number of viable cells was assessed by trypan blue in a Burker chamber (initial viability was $97.5 \pm 2.7 \%, n=36$ ). PC12 cells were gently aspirated in the microdialysis tube as small clusters or single cells (Fig. 8A). At the end of microdialysis experiments, PC12 cells were found to aggregate in big clusters (Fig. 8B). However, no significant decrease of cell viability was observed (final viability was $96.2 \pm 3.4 \%, P<0.05, n=32$ ).

\section{Discussion}

\section{Microelectronics and DA microsensor performance}

The amperometric module of the DCP was optimized for singlesupply, low-voltage operation by distributing the gain between the first and second stages of amplification. Compared with our previous device [17], the gain was distributed between the I/V converter and differentiator. As shown in Fig. 1, fixing Rf to $10 \mathrm{M} \Omega$, a precision differentiator/amplifier (AD626) controlled the amplification factor $(1 \mathrm{nA} / \mathrm{V})$. In this manner, we successfully overcame the lim-
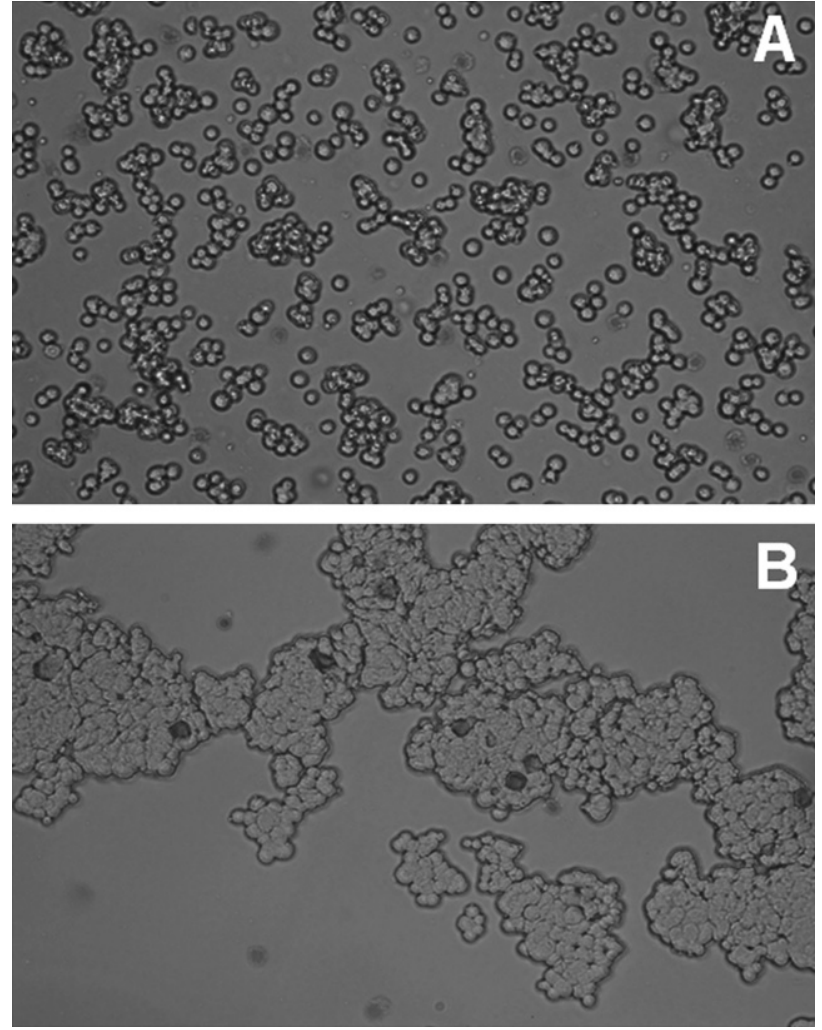

Fig. 8. Microphotographs of PC12 cells before (A) and $6 \mathrm{~h}$ after (B) loading in the microdialysis tube $(75 \mathrm{mM} \mathrm{KCl}$ infusion). PC12 cells were gently aspirated in the tube as small clusters or single cells (A) using a 1-ml Hamilton syringe. At the end of the experiments, PC12 cells were found to aggregate in big clusters. However, no significant decrease of cell viability $(>96 \%)$ was observed.

itations of the previous DCP design [17] related to variations in the resistor values, mainly in the difference circuit. The result is that the module is characterized by gain precision, stability, and an excellent linear response. The system can operate only in oxidation mode, and it is particularly suited to work with direct oxidation sensors such as DA microsensors and biosensors with $\mathrm{H}_{2} \mathrm{O}_{2}$ detection [21]. DA microsensor characteristics were evaluated for up to 3 weeks in vitro, showing good accuracy and precision. DA secreted from PC12 cells is metabolized by catechol-O-methyl-transferase (COMT) to 3-MT [7]; however, no significant interferences were observed on exposing DA sensors to 3-MT. Indeed, this O-methylated metabolite is oxidized at a potential of $+625 \mathrm{mV}$ versus $\mathrm{Ag}$ / $\mathrm{AgCl}$ [15], much higher than DA. A decrease in sensitivity (44\% under quiescent conditions and $45 \%$ under dynamic conditions) compared with initial values (day 1 ) was measured at day 7 and was attributed to microsensor aging. As a result, the symmetry between the two microsensors used in each experiment was maintained for the entire period of testing (7 days). Small baseline differences between sensors were further corrected by software (offset) 60 min before each experiment. F-TECs can be used for 1 week without problems, performing calibrations daily, immediately before experiments, as shown in Results. After 1 month of continuous operation, we observed a reduction in sensitivity (67\% under dynamic conditions vs. day 1) and an increase, sometimes unpredictable, in the asymmetry between the F-TECs, most likely related to RE decline or WE Nafion coating damage.

\section{DA secretion from PC12 cells}

As shown in Materials and Methods as well as in Results, dynamic DA calibration, performed after aspiration of different con- 
centrations of DA in the microdialysis chamber, was used to estimate DA secreted from PC12 cells into the extracellular space. An initial overflow of DA was observed after PC12 cell loading, with a maximal concentration above $1 \mu \mathrm{M} / 1.5 \times 10^{6}$ cells using a perfusion flux of $3 \mu \mathrm{l} / \mathrm{min}$. DA concentrations declined progressively from both outlets during the first 80 to 120 min of PBS-DMEM perfusion. This initial DA peak is related mainly to cell manipulations before loading. Indeed, mechanical stress of PC12 during preparation procedures resulted in an increase in DA overflow. DA clearance from the extracellular fluid has been linked to perfusion flux or rapid metabolism to 3-MT by COMT [6-8] rather than PC12 uptake. Perfusion with the dopamine transporter (DAT) selective inhibitor GBR-12783 did not affect DA clearance time (data not shown). DA then reached a steady-state level with a concentration below $0.15 \mu \mathrm{M} / 1.5 \times 10^{6}$ cells. $\mathrm{KCl}$ exposure, in either the presence or absence of extracellular $\mathrm{Ca}^{2+}$, induced DA secretion proportional to extracellular $\mathrm{K}^{+}$and $\mathrm{Ca}^{2+}$ but also PC12 cell number. Because of the above-mentioned observations, $\Delta C_{\mathrm{L}}$ and $\Delta C_{\mathrm{KCl}}$ could be used to roughly calculate the number of PC12 cells loaded in the microdialysis chamber. These results confirm previous HPLC-based in vitro findings [7] in terms of both DA concentration and secretion time course. Microdialysis tubing can be used continuously over $24 \mathrm{~h}$ without reduction in extraction properties. Unfortunately, PC12 loading can be performed only once because of initial cell adhesion and dialysis membrane fouling. This necessitates the use of a new microdialysis tube for each experiment, whereas the same F-TECs can be used for up to 1 week. Differences in microdialysis tube performance, related to construction procedures, were eliminated by performing calibrations daily, immediately before experiments, as outlined in Materials and Methods. A limitation of the system, related to the use of the microdialysis technique, is that temporal dynamics of DA secretion appear to be slower than that resulting from carbon fiber microsensors placed adjacent to individual PC12 cells [13,14]. However, in comparison with a previous in vitro microdialysis study [5], the small volume of the dialysis chambers and the high number of cells contained in them have the effects of reducing the volume of the extracellular compartment, increasing the concentration gradient of DA through the microdialysis membranes, and increasing the system response time to DA secretion.

\section{PC12 cell viability}

No significant decrease in cell viability was observed at the end of the experiments, as reported in Results. In selected control experiments, PC12 cells were left inside the microdialysis chamber for up to $12 \mathrm{~h}$ in standard perfusion conditions ( $3 \mu \mathrm{l} / \mathrm{min}$ ) without a significant decrease in cell viability. Only after $24 \mathrm{~h}$ was the viability reduced to less than $95 \%$.

\section{Conclusions}

We have presented a novel dual microdialysis in vitro system coupled with DA microsensors for the flow-through detection of DA secreted from PC12 cells. A simultaneous treatment-control experimental protocol was performed to detect $\mathrm{K}^{+}$-evoked DA secretion. The microdialysis system was calibrated and tested under different experimental conditions. This novel apparatus serves as a rapid and reliable model for studying the effects of different drugs on PC12 cell DA secretion. Different cell types might be studied, and DA microsensor could be easily substituted with different microsensors or biosensors, allowing the in vitro detection of other interesting molecules such as nitric oxide, glutamate, glucose, and lactate. The further miniaturization of the electronics and the integration with ultra miniature peristaltic pumps could permit the realization of a low-cost miniaturized device for rapid drug screenings in vitro.

\section{Acknowledgments}

The authors acknowledge the Italian distributors of Linear, Ana$\log$ Devices, Maxim/Dallas, and National for free samples of integrated circuits and Hospal s.p.a. for the kind gift of microdialysis hollow fiber. The research was supported by the University of Sassari (ex 60\% fund) and Fondazione Banco di Sardegna.

\section{References}

[1] R.D. O'Neill, Long-term monitoring of brain dopamine metabolism in vivo with carbon paste electrodes, Sensors 5 (2005) 317-342.

[2] R.M. Wightman, D.L. Robinson, Transient changes in mesolimbic dopamine and their association with "reward", J. Neurochem. 82 (2002) 721-735.

[3] G. Rocchitta, R. Migheli, M.P. Mura, G. Esposito, M.S. Desole, E. Miele, M. Miele, P.A. Serra, Signalling pathways in the nitric oxide donor-induced dopamine release in the striatum of freely moving rats: Evidence that exogenous nitric oxide promotes $\mathrm{Ca}^{2+}$ entry through store-operated channels, Brain Res. 1023 (2004) 243-252.

[4] G. Rocchitta, R. Migheli, M.P. Mura, G. Esposito, B. Marchetti, E. Miele, M.S Desole, M. Miele, P.A. Serra, Signaling pathways in the nitric oxide and ironinduced dopamine release in the striatum of freely moving rats: Role of extracellular $\mathrm{Ca}^{2+}$ and l-type $\mathrm{Ca}^{2+}$ channels, Brain Res. 1047 (2005) 18-29.

[5] S.H. Chiou, C.L. Kao, Y.L. Chang, H.H. Ku, Y.J. Tsai, H.T. Lin, C.J. Yen, C.H. Peng, J.H. Chiu, T.H. Tsai, Evaluation of anti-Fas ligand-induced apoptosis and neural differentiation of PC12 cells treated with nerve growth factor using small interfering RNA method and sampling by microdialysis, Anal. Biochem. 363 (2007) 46-57.

[6] G. Rocchitta, R. Migheli, M.P. Mura, G. Esposito, B. Marchetti, E. Miele, M.S. Desole, P.A. Serra, Role of endogenous melatonin in the oxidative homeostasis of the extracellular striatal compartment: A microdialysis study in PC12 cells in vitro and in the striatum of freely moving rats, J. Pineal Res. 39 (2005) 409418.

[7] P.A. Serra, G. Rocchitta, M.R. Delogu, R. Migheli, M.G. Taras, M.P. Mura, G. Esposito, E. Miele, M.S. Desole, M. Miele, Role of the nitric oxide/cyclic GMP pathway and extracellular environment in the nitric oxide donor-induced increase in dopamine secretion from PC12 cells: A microdialysis in vitro study, J. Neurochem. 86 (2003) 1403-1413.

[8] P.A. Serra, R. Migheli, G. Rocchitta, M.G. Taras, M.P. Mura, M.R. Delogu, G. Esposito, M.S. Desole, E. Miele, M. Miele, Role of the nitric oxide/cyclic GMP pathway and ascorbic acid in 3-morpholinosydnonimine (SIN-1)-induced increases in dopamine secretion from PC12 cells: A microdialysis in vitro study, Neurosci. Lett. 353 (2003) 5-8.

[9] M.P. Gordito, D.H. Kotsis, S.D. Minteer, D.M. Spence, Flow-based amperometric detection of dopamine in an immobilized cell reactor, J. Neurosci. Methods 124 (2003) 129-134.

[10] B.M. Joyce, P.E. Glaser, G.A. Gerhardt, Adderall produces increased striatal dopamine release and a prolonged time course compared to amphetamine isomers, Psychopharmacology 191 (2007) 669-677.

[11] M.D. Doherty, A. Gratton, Medial prefrontal cortical D1 receptor modulation of the meso-accumbens dopamine response to stress: An electrochemical study in freely-behaving rats, Brain Res. 715 (1996) 86-97.

[12] F. Fornai, P. Lenzi, G. Lazzeri, M. Ferrucci, F. Fulceri, F.S. Giorgi, A. Falleni, S. Ruggieri, A. Paparelli, Fine ultrastructure and biochemistry of PC12 cells: A comparative approach to understand neurotoxicity, Brain Res. 1129 (2007) 174.

[13] N. Sasakawa, N. Murayama, K. Kumakura, Characterization of exocytotic events from single PC12 cells: Amperometric studies in native PC12h, DAloaded PC12h, and bovine adrenal chromaffin cells, Cell. Mol. Neurobiol. 25 (2005) 777-787.

[14] K.N. Green, S.C. Taylor, I.F. Smith, C. Peers, Differential coupling of voltagegated $\mathrm{Ca}^{2+}$ channels to catecholamine secretion from separate PC12 cell batches, Neurosci. Lett. 301 (2001) 13-16.

[15] M. Hebel, P.A. Serra, Development of a parallel-computing embedded telemetry system for voltammetric microsensor and biosensor applications, in: M.-I. Baraton (Ed.), Sensors for Environment, Health, and Security: Advanced Materials and Technologies, Springer NATO-ASI Books, Dordrecht, Netherlands, in press.

[16] P.A. Serra, G. Rocchitta, G. Bazzu, A. Manca, G.M. Puggioni, J.P. Lowry, R.D. O'Neill, Design and construction of a low cost single-supply embedded telemetry system for amperometric biosensor applications, Sens. Actuat. B 122 (2007) 118-126.

[17] G. Rocchitta, R. Migheli, S. Dedola, G. Calia, M.S. Desole, E. Miele, J.P. Lowry, R.D. O'Neill, P.A. Serra, Development of a distributed, fully automated, bidirectional telemetry system for amperometric microsensor and biosensor applications, Sens. Actuat. B 126 (2007) 700-709.

[18] S. Ramírez-García, S. Alegret, F. Céspedes, R.J. Forster, Carbon composite electrodes: Surface and electrochemical properties, Analyst 127 (2002) 15121519. 
[19] R. Migheli, C. Godani, L. Sciola, M.R. Delogu, P.A. Serra, D. Zangani, G. De Natale, E. Miele, M.S. Desole, Enhancing effect of manganese on 1-DOPA-induced apoptosis in PC12 cells: Role of oxidative stress, J. Neurochem. 73 (1999) 1155-1163.

[20] K. Yuyama, H. Yamamoto, K. Nakamura, T. Kato, I. Sora, T. Yamamoto, Resistance of PC12 cells against nitric oxide (NO)-induced toxicity in long- term culture: Implication of neuronal NO synthase expression, Neurosci. Lett. 309 (2001) 169-172.

[21] R.D. O'Neill, J.P. Lowry, G. Rocchitta, C.P. McMahon, P.A. Serra, Designing sensitive and selective polymer/enzyme composite biosensors for brain monitoring in vivo, Trends Anal. Chem. 1 (2008) 78-88. 